\title{
Enterprise Niche and E-Business Strategy
}

\author{
Luchuan $\mathrm{Liu}^{1,2}$ and Yu Chen ${ }^{1}$ \\ ${ }^{1}$ School of Information, Renmin University of China, Beijing 100872, P.R. China \\ ${ }^{2}$ School of Information, ShanDong University of Finance, Jinan 250014, P.R. China
}

\begin{abstract}
This paper uses the principles of business ecology to analyze the problems in China's e-business construction and probe in the ways for enterprises in different niches to carry out e-business construction. The ebusiness construction is not the isolated behavior of certain one enterprise and full consideration should be taken into the relations between upper stream and down stream enterprises to form e-business ecosystem. The keystone role of the keystone enterprises in forming e-business ecosystem should be brought into full play. The existence of a great number of nicher enterprises marks a healthy e-business ecosystem, and the dominating enterprises should be restricted and then transformed into the keystone enterprises. Different enterprises in different niches should have different e-business strategies. The hetero-organizations of the government are of great importance to the formation and health of ebusiness ecosystem.
\end{abstract}

Keywords: E-business, Business ecosystem, Enterprise niche, Self-organization and Hetero-Organization

\section{INTRODUCTION}

Developing e-business is a significant move for bringing along industrialization through information technology, transforming the ways of economic growth, improving the operating quality and efficiency of China's national economy and taking the new road to industrialization, and it is of great significance for attaining the grand objectives of building a well-off society in an all-round way. China has made considerable progress in e-business, but there still exists a great gap compared with the developed countries. Particularly, it has been the question obfuscated the people how the traditional enterprises of different types carry out e-business construction. As to how to analyze and solve these questions, the business ecology provides us with the way of thinking that can be used for reference. 


\section{AN OVERVIEW OF BUSINESS ECOSYSTEM}

\subsection{Definition of Business Ecosystem}

Over long years, life has evolved from monad into alga, fungus, plant, animal and human. The fittest survives in the natural selection and the circle of life continues in endless succession. All these form the rich and colorful ecosystem. The term "ecosystem" was first introduced by the British ecologist, A. G Tanlsly (1945). It refers to a whole with certain size and structure formed by the biotic community and its environment within a given space and time, in which all the living organisms grow by the aid of material cycle, energy transfer and information transmission and mutually interact and influence and depend on each other, forming a complex with self-adapting, self-regulating and self-organizing functions. Similar to ecosystem, James F. Moore (1996), a US expert on enterprise strategy, put forward the concept of "business ecosystem" when he considered the problem of modern enterprise competition from the viewpoint of ecology. He defined it as "an economic community supported by a foundation of interacting organizations and individuals". [1] Moor's enterprise business ecosystem includes the suppliers, main manufacturers, competitors, customers, scientific research institutions, colleges and universities, administrative departments, government and other stakeholders. Yang Zhongzhi (2003), a Chinese scholar, defined the business ecosystem as a system formed by enterprises, consumers, markets as well as their natural, social and economic environment [2].

\subsection{Major Characteristics of Business Ecosystem}

Just like ecosystem, the business ecosystem is a complex adaptive system, which is composed of independent main bodies and has no central control. Every enterprise operates in the way of self-adaptation and demonstrates the characteristics of the system through self-organization.

Multiple Agents. The business ecosystem is a system composed of many interest main bodies such as enterprises and consumers. The main bodies are active and living entities.

Adaptability. In the ecosystem, adaptability represents the instinct of the living beings producing reaction to the environment and its changes and is the basic way for the existence and evolution of the living beings. The enterprises and the living population or individuals share the same features of existence. The adaptability of enterprises in the business ecosystem represents both the suitability of enterprise existence and development under given environment and the harmoniousness of coexistence with other enterprises. This kind of adaptability reflects the equilibrium and stability obtained in the interaction between enterprises and environment and between enterprises and enterprises and it also reflects the existence and development of the main bodies in mutual adaptation in the system. 
Self-Organization and Hetero-Organization. The self-organization of the living population constitutes one of the main ways of living beings' existence and evolution and the business ecosystem is no exception. The self-organizational features of the business ecosystem are the course and results of spontaneous and independent evolution of enterprises toward intensified structure and order. Self-organization is the essential property of the business ecosystem, but in the course of its formation and development, the business ecosystem can never do without the active guide and promotion of hetero-organization. The so-called hetero-organization of the business ecosystem refers to the fact that various environmental factors act through the selforganizational mechanism inside the business ecosystem and consequently influence the formation and development of the whole system. The hetero-organization is not a spontaneous and independent process of the system; instead, it is the organizational process or result driven by the external power.

Opening. Opening is the prerequisite for the emergence of self-organization. The social system is an open system. So long as the external environment exerts influence on the business ecosystem with a given boundary and such influence exceeds a certain value limit, the phenomenon of self-organization will emerge, which consequently will lead to technological progress, changes in operating models, increase of competitiveness and evolution of enterprises.

Diversity. The diversity of the living beings refers to all the animals, plants and microorganisms in the biosphere of the earth and their genes and existence environment. It includes the gene diversity, species diversity and ecological environment diversity. The reason why a biological ecosystem can continuously multiply and evolve lies in its latent food chain. Similarly, the latent value chain in the business ecosystem connects all the independent, living and different enterprises. The enterprises in the business ecosystem jointly create, transfer and share value and provide products and services for the customers. The diversity of business ecosystem can also be seen in the fact that the realistic competition has become the competition among different business ecosystems that provide the same or substitutable products or services.

\subsection{Niches of Different Enterprises in Business Ecosystem}

To scramble for the common sunshine resource, the plants in the tropical rainforest compete with each other and depend on each other. The large arbors are heliophilous plant and their crowns stretch high in the sky to absorb more sunshine while the heliophobous plants such as bushes, herbs or lichens hide themselves in the shade of the arbors where they can both absorb sunshine and avoid being exposed to the burning sun. Different species and individuals in the ecosystem have their own different niches and competition strategies. In literature [5], Marco Lansiti and Roy Levien believe that the enterprises are usually in three niches in the business ecosystem: Keystone, Dominator, and Nicher.

(1) The keystone species in the biological ecosystem are not the dominators of community but the key links of the ecological community, and they influence the health of the whole ecosystem through the food chain network. Similarly, in the business ecosystem, the keystone enterprises that act as keystones lie in the central 
position. Through their core capabilities (technology, brand, standard, etc), they build the value network platform and share value with other numerous member enterprises while creating value themselves. The value created by the keystone enterprise is of crucial importance for the health of the whole system. The business ecosystem with Microsoft-IBM-Intel as the keystone attracts numerous member enterprises by opening their standards and platforms. By continuously launching and updating the standards and platforms, they continuously create and share value, promote the diversity of the system and maintain favorable competition and vigor inside the system. On the contrary, Apple refuses to open its operating system and attempts to independently produce the products integrating the hardware, operating system and applications and finally, it fails in the competition.

(2) The dominating enterprises usually have special positions in the system. They attempts to control and possess and then eliminate and annihilate numerous node enterprises and the result is that they destroy the ecological diversity. Such enterprises can create extremely limited value for the system but try to maximally snatch value from the system. Ultimately, they will destroy the health of the ecosystem, result in the collapse of the whole ecosystem and ruin their own fate. The companies such as Apple and Enron can serve as the best examples in this aspect.

(3) The term "nicher" was officially put forward by the famous US management scholar, Peter Drucker, in his Innovation and Entrepreneurship. In his opinion, the principle for small and medium-sized enterprises to select business fields should be the pursuit of "nicher". According to the generation mechanism of nicher, they select the business fields suitable for their own development. They should make full use of and bring into full play their potential advantages and produce the products that are entirely different from those of their competitors but possess their own individuality. The nicher enterprises form the main body of the system. Numerous such enterprises adopt the strategy of high specialization and naturally depend on keystones and other enterprises. Only by relying on the resources provided by other enterprises, they can spare energy to specialize in the narrow segmented market and obtain their tiny space through differentiation. Numerous nicher enterprises reflect the diversity of business ecosystem and form the foundation for the health, flourish and prosperity of business ecosystem.

According to Marco Lansiti and Roy Levien, there are three criteria for judging the health conditions of business ecosystem: the first is productivity, which is usually measured with return on investment; the second is life force, namely, the ability of the system in resisting various interference and destruction. It can be judged according to the number of enterprises in the system; and the third is the ability in creating nicher markets, that is whether it can create more segmented markets.

\section{ANALYSIS OF MAJOR PROBLEMS EXISTING IN CHINA'S E-BUSINESS CONSTRUCTION FROM THE PERSPECTIVE OF BUSINESS ECOLOGY}

For the concept and essence of e-business, there has been no unanimous definition to date. In the contention of various opinions, Z. Wass (1996), the editor-in-chief of 
Journal of Management Information Systems and E-Business magazine made a concise and comprehensive answer. He believes that "e-business refers to all the activities of sharing business information, maintaining business relationship and making economic contact based on information communication network". The concept of $Z$. Wass has been widely accepted by the scholars in the academic research fields of information management and information systems. It shows that e-business is a kind of business but it is not only the buying and selling activities among enterprises or consumers. What is more important is that it is an economic behavior with the purpose of establishing new economic contact and relationship on the information network [4]. Therefore, it can be fully described and studied by the aid of the principles of business ecosystems. Of the numerous problems existing in China's e-business construction, we shall focus on the main ones of keystone enterprises, small and medium-sized enterprises and dominating enterprises in the e-business construction, and make the following analyses:

\subsection{Main Problems of Keystone Enterprises in E-Business Construction}

The keystone enterprises and industries attach more importance to the construction of e-business systems and spend a huge amount of money in the construction of IT application and e-business inside the enterprises. But the problem is that enterprises or industries cannot share their information and there lack the standards for information exchange. This has resulted in many "isolated information islands" and influenced the play of e-business functions of the whole society. The Chinese monopoly and semimonopoly enterprises such as railway, civil aviation, communications and banking have developed their own e-business systems including online ticket booking and online banking. However, the information can only be interchanged vertically within enterprises and industries and there lacks the channel for horizontal interchange. The reason is that no relevant e-business ecosystems have been formed. Just as what has been mentioned earlier, opening is the prerequisite for ecosystem. Without opening, the keystone enterprises will not be able to share value with other enterprises while creating value or attract the numerous nicher enterprises to participate. And there will emerge no self-organization, and consequently there will be no mutual adaptation among the member enterprises within business ecosystem or mutation toward higher levels on this basis. Certainly, there will be no information exchange among different business ecosystem. The China's railway ticket-selling system represents the computer ticket selling and booking system that has the largest investment, the widest coverage and the most advanced technology in the world. Undoubtedly, it has played an active role in solving the problem of the difficulty in buying tickets. However, due to monopoly, it hasn't been consequently developed into a healthy e-business ecosystem. What deserves to be used for our reference is the SABRE and Apollo computer ticket booking systems of American Airlines and United Airlines. In the mid-1980s, the ticket booking systems of these two airlines occupied nearly $80 \%$ of the market shares in the whole US, and then they opened their systems. Other airline companies leased the systems of these two companies one after another. Supported by the computer ticket booking system and with these two airlines as keystone, the ebusiness ecosystem was formed, which consists of many species such as banks, 
catering, hotels, taxis, travel agencies, weather services and information consultancy [6].

\subsection{Main Problems of Small and Medium-Sized Enterprises in E-Business Construction}

From the lack of knowledge of e-business construction to the simple rush for it, the e-business construction in China's small and medium-sized enterprises has experience the process of being cold to hot and then to cold. At the beginning, they lacked the knowledge of e-business and then some of them began to accept the e-business concept, but they adopted the simple strategy of rushing for it by invest material and financial resources in purchasing equipment, leasing channels and building websites. In their opinions, after the websites are opened, the marketing channels will be flattened and their market shares will be enlarged. However, things do not turn out as they wish. Their websites are seldom visited and quickly immersed in the sea of information on the Internet. Then they begin to doubt of e-business. Any species cannot break away from the population, community and ecological environment for their existence and different species have different niches and ways of existence. In their own business ecosystems, the small and medium-sized enterprises concentrate themselves on the narrow segmented markets and naturally depend on keystone enterprises. Therefore, in the e-business construction, they should first consider their characteristics, emphasize the construction of their internal information systems and realize the connection with such systems as SCM and ERP of the keystone enterprises, forming the relevant e-business ecosystem. Secondly, in the e-business construction, it is unnecessary for the small and medium-sized enterprises to imitate the way of keystone enterprises in a mechanical and simple manner. When people talk about the e-business modes, they always start with the business model, service contents and current scale of a certain website. In fact, it is impractical and unreasonable to analyze the development of e-business by centering on websites.

\subsection{Main Problems of Dominating Enterprises in China's E-Business}

The Internet bottleneck coexists with the dominating enterprises. The e-business is the business activities supported by the Internet. There still exists the bottleneck in China's Internet portal bandwidth, IP address, and bandwidth of Internet exchange among China's several large Internet operating companies. The monopoly of these companies as dominators has intensified the congestion of bottleneck all the more, there still exist a lot of unreasonable aspects in charging the channel rent and network information fee, and the service quality is hardly guaranteed. All these have impacted the e-business construction in enterprises. When the Chinese Internet industry has just started, China Telecom, the then network operator was the "value dominator". If the users browsed the foreign websites through ISP (Internet Service Provider), the amount of expense ISPs collected from the users could hardly set off the trunk network use fee paid to China Telecom. The longer the users visited the foreign websites, the more money ISPs would lose. As a result, China's ISPs such as 
InfoHighWay (IHW) and East Net successively closed down or changed their business patterns. At the same time, however, there were 7100 ISPs in North America in 2000, and even such Internet service magnate as AOL was made. In 2000, China Mobile, one of the network operators, began to adopt the strategy of shifting itself from a dominating enterprise to a keystone one. By gathering thousands of ISPs to provide value-added services such as short message, it has promoted the prosperity of numerous ISPs and its performance has been greatly enhanced. Thus a healthy ebusiness ecosystem began to emerge.

\section{USING THE THEORY OF BUSINESS ECOLOGY TO GUIDE E-BUSINESS}

\subsection{Bringing Into Play Self-Adaptability of Enterprises to Construct Varied and Colorful E-Business Ecosystems}

E-business ecosystem construction should be brought into full play. The keystone enterprises are the keystone in e-business ecosystem and their leading role in purchase, sale and other aspects should be brought into full play. Based on industry chain and focused on supply chain management, the keystone enterprises should integrate the related resources of upper stream and down stream connected enterprises to realize the combination of business flows and mutual connection of information systems among the enterprises, promote e-business among them and enhance the market response ability and overall competitiveness of the enterprise groups. The open and healthy e-business ecosystem should be constructed, in which the keystone enterprises are the keystone, there are numerous symbiotic nicher enterprises and the value is shared. To bring into full play the role of keystone enterprises in the ebusiness construction is also significant in that it can help to develop the standards for sharing and exchanging information resources and solve the problem of "isolated information island". In fact, the standards are the outcome of self-organization. As the keystone lies in the central position of ecosystem, different species in the business ecosystem can conscientiously follow the standards stipulated by keystone for interdependence, symbiosis and mutual flourish, thus forming the de facto standards and promoting the course of e-business standardization. In May 2002, Jinan EBusiness and Modern Logistics Application Demonstration Project with Sanlian Group as the leader was officially launched. It was the "regional e-business and modern logistics demonstration project", one of the national key scientific projects during the Tenth Five-Year Plan. Numerous magnates from Chinese and international upper stream enterprises on the industry chain of electrical appliances as well as numerous down stream distributors signed agreements with Sanlian Group, the undertaker of the demonstration project, to jointly construct the new supply chain system for production, circulation and consumption of electrical appliances and integrating information flow, capital flow and logistics, so as to attain the objective of common growth and gains of manufacturing enterprises, circulation enterprises and 
consumers of electrical appliances, fully integrating the resources of upper stream and down stream enterprises in domestic and foreign electrical appliances industry, driving down the total costs of supply chain and increasing the overall operating efficiency of supply chain. So far, by the aid of e-business logistics platform, Sanlian has formed alliance with 56 upper stream enterprises and 128 down stream enterprises and realized information sharing. More than ten banks serving these enterprises also joined the alliance. In December 2005, the Conference on Acceptance of Pilot Enterprises Engaged in the "Important Technology Standard Research, organized by the State Ministry of Science and Technology, State Administration of Quality Supervision, Inspection and Quarantine, and Standardization Commission of China, was held in Beijing. The "important technology standard research" project specialized in e-business and modern logistics and undertaken by Shangdong Sanlian Group, the only pilot unit in modern service industry, smoothly passed the final checking and acceptance.

More efforts should be made to support the construction of the third party ebusiness service platforms for SMEs and the application of e-business in these enterprises. Such service platforms can solve the problems of SMEs in investment, personnel and other aspects, promote their application of e-business, improve business efficiency, reduce transaction costs and push forward their IT application. That is to say, the development of e-business particularly needs the same development of the institutions that provide public services. This is especially important for the Chinese enterprises which are scattered and have low IT application basis. Practice shows that it is impossible for one enterprise succeed in the e-business particularly the e-business oriented to consumers only through the isolated construction of the website. Different species should first form population and community and then form diverse modes of life. And the third party e-business service platform can just become the keystone that plays a key role in the formation of modes. The nicher SMEs can be absorbed in the segmented markets where they have their own core capabilities and outsource online marketing, authenticated payment and logistic distribution to the third party e-business service enterprises. The online supermarket, which relies on the multiple species and modes of the third party e-business service platform and which can gather sentiment, should be a development orientation of e-business.

The dominating enterprises should be restricted and then transformed into keystone enterprises. In the e-business ecosystem, the enterprises or industries in the natural status of monopoly or semi-monopoly often play the role of dominators. To solve this problem, on the one hand, efforts should be made to restrict their behaviors through the interference of the government, bring into play the role of hetero-organization and limit monopoly to maintain the health of business ecosystem; on the other hand, the dominating enterprises should also be fully aware that the current overall operation environment for the enterprises is a symbiosis system of interconnection and interdependence, in which the value is jointly created and shared. The future competition will not be the competition of individual competition but the confrontation among business ecosystems. In working out strategies, the enterprises should not only proceed from their own interests but should also take into consideration the healthy development of their partners and the whole business ecosystem. Only when the business ecosystem is healthy can every species and 
individual in it thrive, thus realizing the role shift from dominating enterprises to keystone enterprises.

\subsection{Improving Policies, Laws and Regulations and Standardizing E-Business Development}

Just as a little life needs careful nursing, the e-business construction and the formation and healthy development of its ecology also needs the hetero-organization of the government to create the favorable environment for the development of ebusiness. For this purpose, efforts must be made to conscientiously carry out the Electronic Signature Law of the People's Republic of China, make research on the issues of laws and regulations related to electronic transaction, credit management, security certification, online payment, taxation, market access, privacy protection and information resource management and stipulate the relevant laws and regulations as soon as possible; accelerate the stipulation of the measures for managing the relevant online business operations; promote the construction of legal service and guarantee systems such as online arbitration and notarization; crack down on the illegal operations in the field of e-business as well as the criminal activities that jeopardize the national security and harm the immediate interests of the mass people to ensure the normal order of e-business.

The mechanism for e-business investment should be improved. Efforts should be made to establish and improve the multidirectional and multi-channel investment and financing mechanism suitable for the development of e-business and study and stipulate the relevant policies that can promote the mutual support and coordinated development of the related enterprises in banking and e-business. The role of the government investment in promoting the investment by enterprises and society should be enhanced and the principal position of enterprises in e-business investment should be further intensified.

\section{CONCLUSIONS}

The construction of e-business is not the isolated behavior of one enterprise and full consideration should be taken into the relations between the upper stream and down stream enterprises to form e-business ecosystem. The keystone role of the keystone enterprises in forming e-business ecosystem should be brought into full play. The existence of a great number of nicher enterprises marks a healthy e-business ecosystem, and the dominating enterprises should be restricted and then transformed into the keystone enterprises. Different enterprises in different niches should have different strategies for e-business construction. The hetero-organizations of the government are of great importance to the formation and health of e-business ecosystem. 


\section{REFERENCES}

1. M. Begon, J.L. Harper, and C.R. Townsend, Ecology: individuals, populations and communities (Blackwell Scientific publications: Boston, 1996).

2. J.F. Moore, The Death of Competition: Leadership and Strategy in the Age of Business Ecosystem (Harper Collins Publishers: New York, 1996).

3. Z. Yang, Introduction on enterprise ecological system (Science Press: Beijing, 2003)

4. J.H. Holland, Hidden Order: How Adaptation Build Complexity (Shanghai Scientific \& Technological Publishing House: Shanghai, 2000).

5. M. Lansiti and R. Levien, The Keystone Advantage: What the New Dynamics of Business Ecosystem Mean for Strategy, Innovation, and Sustainability (Harvard Business School Press: Boston, Massachusetts, 2004).

6. M. Fang, E-business and Traditional enterprise (Tsinghua University Press: Beijing, 2003).

7. M. Hammer and J. Charmpy, Reengineering the corporation: A manifesto for business revolution (HarperCollins: New York, 1993).

8. Henderson and N.S. Venkatraman, Alignment: Leveraging Information technology for transforming organizations, IBM Systems Journal. Volume 32, Number 1, pp.472-484, (1993).

9. P. Fingar, The Death of " $e$ " and the Birth of the Real New Economy (Meghan-Kiffer Press: Florida, 2001). 